\title{
Line-assisted complete closure of duodenal mucosal defects after underwater endoscopic mucosal resection
}

Duodenal endoscopic mucosal resection (EMR) carries a high risk of adverse events, including delayed perforation $[1,2]$. Because complete clip closure of mucosal defects can reportedly prevent post-procedural adverse events in the colorectum, we established a line-assisted complete closure (LACC) technique for large mucosal defects after colonic endoscopic submucosal dissection [3]. LACC can be useful in the duodenum, but its feasibility is unknown. Therefore, we investigated the feasibility of LACC of mucosal defects after underwater EMR in the duodenum.

Eight patients with $20-\mathrm{mm}$ or larger duodenal tumors underwent LACC of mucosal defects after underwater EMR ( Fig. 1; Video 1). LACC was performed as follows [3]. First, a nylon line was tied to a clip (HX-610-090; Olympus, Tokyo, Japan) mounted on an applicator (HX-110LR; Olympus). The clip was then retracted into the applicator and inserted into the accessory channel. The clip-and-line system was placed on the normal mucosa at the proximal side of the defect ( $\triangleright$ Fig.2a). Another clip (without a line) was used to anchor the line to the other side of the normal mucosa. Both clips were gathered together by gently pulling the line ( $\mathbf{F i g . 2} \mathbf{b}$ ). Additional clips were placed to achieve complete closure ( $\triangleright$ Fig. $\mathbf{2 c}$ ). Finally, the line tied to the clip was cut using scissor forceps (FS-3L-1; Olympus) ( $\triangleright$ Fig. 2 d). Complete closure was achieved in seven patients (88\%) without adverse events; however, one $35-\mathrm{mm}$ defect could not be closed completely, and delayed bleeding occurred. This patient was the first one to undergo duodenal LACC using a single clip-and-line system. We have recently used two or three clipand-line systems to close large defects and have achieved complete closure [4]. Although an over-the-scope clip can reportedly be useful to prevent delayed perforations after duodenal EMR [5],
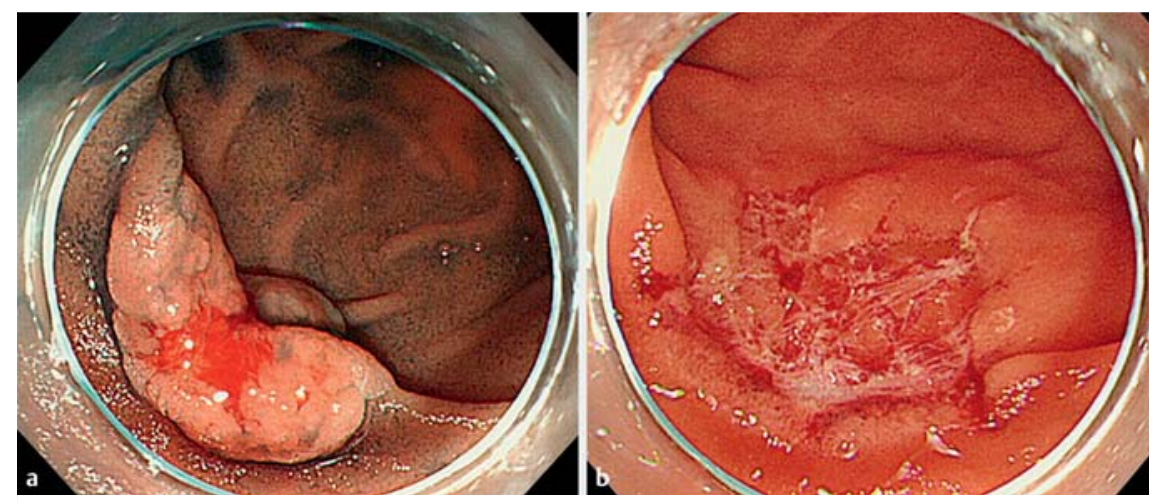

- Fig. 1 The duodenal mucosal defect after underwater endoscopic mucosal resection (EMR). a Esophagogastroduodenoscopy showed a slightly elevated lesion $25 \mathrm{~mm}$ in size at the second portion of the duodenum. $\mathbf{b}$ The same area after piecemeal underwater EMR had been performed.

high-end devices are required and the size is limited. LACC is simple, affordable, and seems feasible for large duodenal mucosal defects after underwater EMR.

Endoscopy_UCTN_Code_TTT_1AO_2AI

Competing interests

None

\section{The Authors}

Yasushi Yamasaki, Yoji Takeuchi, Noriya Uedo, Noboru Hanaoka, Koji Higashino, Ryu Ishihara, Hiroyasu lishi

Department of Gastrointestinal Oncology, Osaka Medical Center for Cancer and Cardiovascular Diseases, Osaka, Japan 


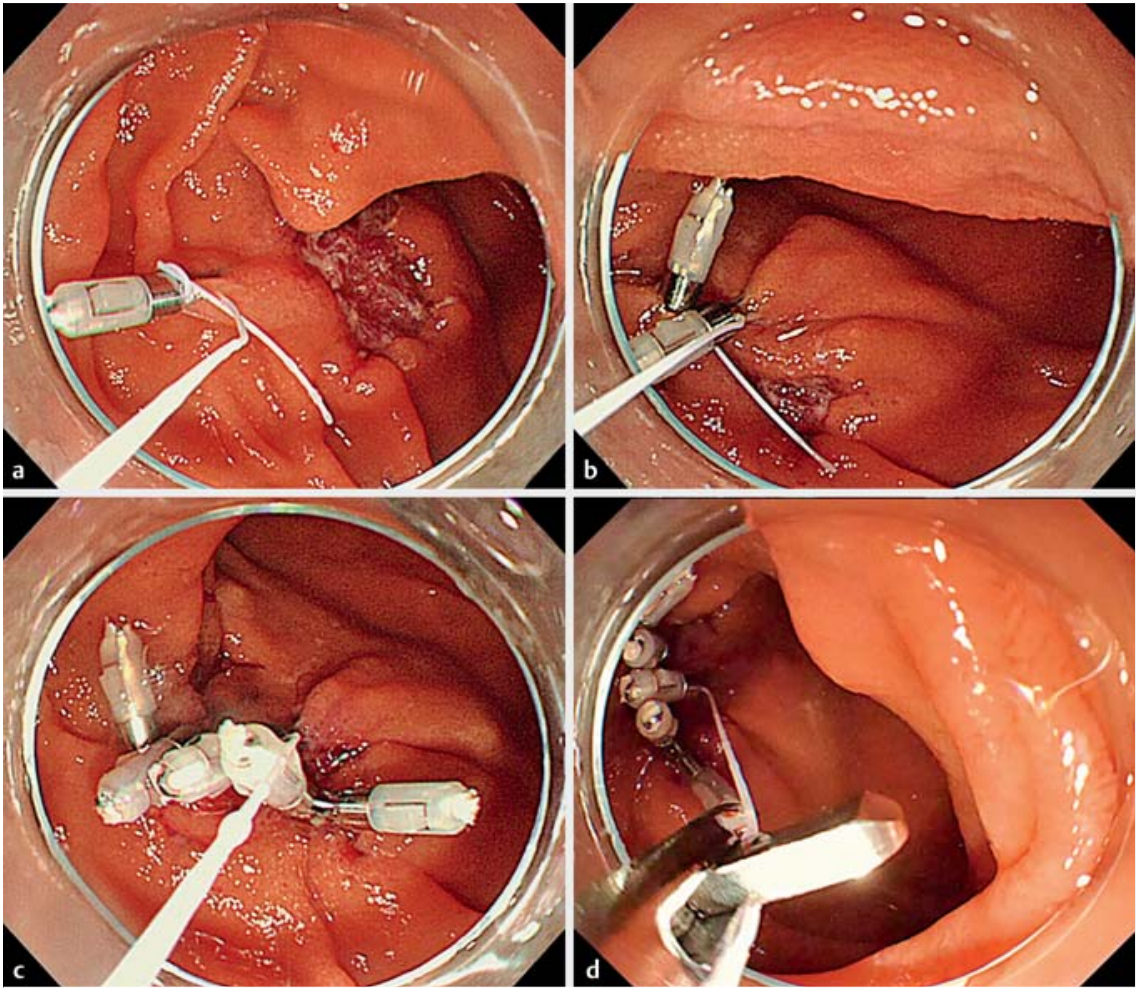

Fig. 2 The line-assisted complete closure technique. a A clip-and-line system was placed on the normal mucosa at the proximal side of the duodenal defect. $\mathbf{b}$ The line was anchored to the distal side of the mucosa using another clip, and both sides of the defect were gathered together by pulling the anchored line. $\mathbf{c}$ Additional clips were placed to achieve complete closure. If the remaining defect was too large for complete closure using clips, another clip-and-line system was applied in the same way to close the defect. $\mathbf{d}$ The line attached to the clip was cut using scissor forceps.
Corresponding author

\section{Yoji Takeuchi, MD}

Department of Gastrointestinal Oncology, Osaka Medical Center for Cancer and Cardiovascular Diseases, 1-3-3 Nakamichi, Higashinari-ku, Osaka 537-8511, Japan, Fax: +81-6-69814067,

takeuti-yo@mc.pref.osaka.jp

\section{References}

[1] Inoue T, Uedo N, Yamashina T et al. Delayed perforation: A hazardous complication of endoscopic resection for non-ampullary duodenal neoplasm. Dig Endosc 2014; 26: $220-227$

[2] Nonaka S, Oda I, Tada K et al. Clinical outcome of endoscopic resection for nonampullary duodenal tumors. Endoscopy 2015; 47: $129-135$

[3] Kato M, Takeuchi Y, Yamasaki Y. Line-assisted complete closure of a large colorectal mucosal defect after endoscopic submucosal dissection. Dig Endosc 2016; 28: 686

[4] Yamasaki Y, Takeuchi Y, Kato M et al. Lineassisted complete closure of large gastric mucosal defects by use of multiple clip-andline technique. VideoGIE. DOI: http://dx.doi. org/10.1016/j.vgie.2016.08.008

[5] Mori H, Shintaro F, Kobara H et al. Successful closing of duodenal ulcer after endoscopic submucosal dissection with over-the-scope clip to prevent delayed perforation. Dig Endosc 2013; 25: 459-461

\section{Bibliography}

DOI http://dx.doi.org/10.1055/s-0042-120707

Endoscopy 2017; 49: E37-E38

(c) Georg Thieme Verlag KG

Stuttgart · New York

ISSN 0013-726X 